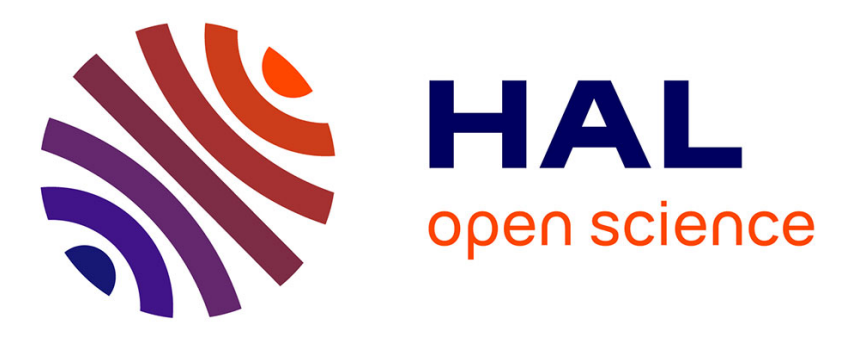

\title{
The VE/VCO 2 slope: a useful tool to evaluate the physiological status of children with congenital heart disease
}

Arthur Gavotto, Helena Huguet, Marie-Christine Picot, Sophie Guillaumont, Stefan Matecki, Pascal Amedro

\section{To cite this version:}

Arthur Gavotto, Helena Huguet, Marie-Christine Picot, Sophie Guillaumont, Stefan Matecki, et al.. The VE/VCO 2 slope: a useful tool to evaluate the physiological status of children with congenital heart disease. Journal of Applied Physiology, 2020, 129 (5), pp.1102-1110. 10.1152/japplphysiol.00520.2020 . hal-02939362

\section{HAL Id: hal-02939362 https://hal.science/hal-02939362}

Submitted on 29 Jul 2021

HAL is a multi-disciplinary open access archive for the deposit and dissemination of scientific research documents, whether they are published or not. The documents may come from teaching and research institutions in France or abroad, or from public or private research centers.
L'archive ouverte pluridisciplinaire HAL, est destinée au dépôt et à la diffusion de documents scientifiques de niveau recherche, publiés ou non, émanant des établissements d'enseignement et de recherche français ou étrangers, des laboratoires publics ou privés. 


\title{
The $\dot{\mathrm{V}} \mathrm{E} / \dot{\mathrm{V}}_{\mathrm{CO}_{2}}$ slope: a useful tool to evaluate the physiological status of children with congenital heart disease
}

\author{
Arthur Gavotto, ${ }^{1,2}$ Helena Huguet, ${ }^{3,4}$ Marie-Christine Picot, ${ }^{3,4}$ Sophie Guillaumont, ${ }^{1,5}$ Stefan Matecki, ${ }^{2,6}$ \\ and Pascal Amedro ${ }^{1,2,4,6}$ \\ ${ }^{1}$ Paediatric and Congenital Cardiology Department, M3C Regional Reference CHD Centre, University Hospital of Montpellier, \\ Montpellier, France; ${ }^{2}$ PhyMedExp, CNRS, INSERM, University of Montpellier, Montpellier, France; ${ }^{3}$ Epidemiology and \\ Clinical Research Department, University Hospital of Montpellier, Montpellier, France; ${ }^{4}$ Clinical Investigation Centre, \\ INSERM, University of Montpellier, Montpellier, France; ${ }^{5}$ Paediatric Cardiology and Rehabilitation Unit, St-Pierre Institute, \\ Palavas-Les-Flots, France; and ${ }^{6}$ Paediatric Functional Exploration Laboratory, Physiology Department, University Hospital of \\ University of Montpellier, Montpellier, France
}

\begin{abstract}
- Cardiopulmonary exercise test (CPET) is becoming a key examination to assess physical capacity and disease severity in pediatric cardiology. The $\dot{\mathrm{V}} \mathrm{E} / \dot{\mathrm{V}}_{\mathrm{CO}}$ slope has been increasingly used as a surrogate marker for morbidity and mortality in adult heart failure, pulmonary arterial hypertension, and for adult patients with congenital heart disease (CHD). Nevertheless, the use of the $\dot{\mathrm{V}}_{\mathrm{E}} / \dot{\mathrm{V}}_{\mathrm{CO}_{2}}$ slope in children remains limited in the absence of reference values and clearly identified clinical determinants. This study aimed to compare the $\dot{\mathrm{V}} \mathrm{E} / \dot{\mathrm{V}}_{\mathrm{CO}}$ slope in a pediatric cohort with $\mathrm{CHD}$ to that of age- and gender-adjusted healthy controls. We also intended to identify the clinical and CPET variables associated with $\dot{\mathrm{V}} \mathrm{E} / \dot{\mathrm{V}}_{\mathrm{CO}}$ slope in this population. This cross-sectional study was carried out between November 2010 and September 2015 in two tertiary care pediatric cardiology reference centers. A total of 700 children were enrolled (399 $\mathrm{CHD}$ and 301 healthy controls). The mean $\dot{\mathrm{V}} \mathrm{E} / \dot{\mathrm{V}}_{2} \mathrm{CO}_{2}$ slope was significantly higher in the CHD subjects than in healthy subjects (31.6 \pm 4.8 vs. $29.3 \pm 4.8 ; P<0.001)$. The $\dot{\mathrm{V}}_{\mathrm{E}} / \dot{\mathrm{V}}_{\mathrm{CO}_{2}}$ slope was higher in children with significant pulmonary regurgitation, tricuspid regurgitation, right ventricular hypertension, and right ventricle outflow tract (RVOT) obstacle. In the $\mathrm{CHD}$ group, $\dot{\mathrm{V}}_{\mathrm{E}} / \dot{\mathrm{V}}_{\mathrm{CO}_{2}}$ slope increase was associated with body mass index, the presence of a RVOT obstacle, the number of cardiac catheter procedures, as well as low age, forced vital capacity, tidal volume, and $\mathrm{PET}_{\mathrm{CO}_{2}}$. Increased $\dot{\mathrm{V}}_{\mathrm{E}} / \dot{\mathrm{V}}_{\mathrm{CO}}$ slope was predominantly in children with single ventricle and/or residual right heart abnormalities, suggesting that maldistribution of pulmonary blood flow during exercise is an important CHD-unique determinant of $\dot{\mathrm{V}} \mathrm{E} / \dot{\mathrm{V}}_{\mathrm{CO}_{2}}$ slope.
\end{abstract}

NEW \& NOTEWORTHY Using $\dot{\mathrm{V}} / \dot{\mathrm{V}}_{\mathrm{CO}_{2}}$ slope is useful for children with congenital heart disease. $\dot{\mathrm{V}} \mathrm{E} / \dot{\mathrm{V}}_{\mathrm{CO}}$ slope is sensitive to pulmonary blood flow maldistribution during exercise, this concerns congenital heart disease with pulmonary regurgitation, tricuspid regurgitation, right ventricular hypertension, and right ventricle outflow tract obstacle. $\dot{\mathrm{V}} \mathrm{E} / \dot{\mathrm{V}}_{\mathrm{CO}_{2}}$ slope is a good parameter to follow single ventricles and right heart residual lesions (tetralogy of Fallot; pulmonary atresia; truncus arteriosus...).

Correspondence: A. Gavotto (a-gavotto@chu-montpellier.fr). cardiopulmonary exercise test; congenital heart disease; pediatrics; ventilatory efficiency; $\dot{\mathrm{V}} \mathrm{E} / \dot{\mathrm{V}}_{\mathrm{CO}_{2}}$ slope

\section{INTRODUCTION}

Cardiopulmonary exercise test (CPET) is becoming a key examination to assess physical capacity and disease severity in pediatric cardiology (21). Indeed, CPET provides an evaluation of the maximal oxygen uptake $\left(\dot{\mathrm{V}}_{\mathrm{O}_{\text {max }}}\right)$, which correlates with both quality of life and prognosis (4). Currently, $\dot{\mathrm{V}}_{\mathrm{O}_{2 \max }}$ commonly stands as the main parameter to determine the severity of congenital heart disease (CHD), as aerobic exercise capacity is predominantly impaired in the most complex CHD (2).

However, maximal exercise may be difficult to obtain, especially in children, and peak $\mathrm{VO}_{2}$ is more frequently used in routine follow-up, as well as in the pediatric literature (5) Moreover, maximal CPET may not accurately reflect in daily life physical activities, therefore sub-maximal ventilatory parameters, such as the ventilatory anaerobic threshold (VAT), the oxygen uptake efficiency slope (OUES) (15), or the ventilatory efficiency $\left(\dot{\mathrm{V}} \mathrm{E} / \dot{\mathrm{V}}_{\mathrm{CO}_{2}}\right.$ slope), have shown some interest in patients with cardiac conditions. Indeed, based on their VAT, children with CHD are not limited in their submaximal exercise capacity (23) but remain three times more concerned than the general population with limitation of physical fitness (2).

The $\dot{\mathrm{V}} \mathrm{E} / \dot{\mathrm{V}}_{\mathrm{CO}_{2}}$ slope has been increasingly used as a surrogate marker for morbidity and mortality in adult heart failure and pulmonary arterial hypertension, including for adult patients with $\mathrm{CHD}(22,24,27)$. The $\dot{\mathrm{V}}_{\mathrm{E}} / \dot{\mathrm{V}}_{\mathrm{CO}}$ slope corresponds to the ventilation increase in response to $\mathrm{CO}_{2}$ production, and thus reflects increased ventilatory drive (37). Accurate determination of $\dot{\mathrm{V}} \mathrm{E} / \dot{\mathrm{V}}_{\mathrm{CO}}$ slope does not require maximal exercise, and its changes are related to increases in the number and the sensitivity of central chemoreceptors, the ventilatory dead-space, and metabolic demand linked to muscular $\mathrm{CO}_{2}$ production during exercise $(9,29)$. Nevertheless, despite previous studies in healthy children $(7,10,28,34)$, the use of the $\dot{V}_{\mathrm{E}} / \dot{\mathrm{V}}_{\mathrm{CO}}$ slope in children has been limited due to the lack of normal pediatric values and clearly identified clinical determinants (32). As a consequence, 
the prognosis value of $\dot{\mathrm{V}}_{\mathrm{E}} / \dot{\mathrm{V}}_{\mathrm{CO}_{2}}$ slope in the pediatric population remains undetermined.

This study aimed to evaluate the $\dot{\mathrm{V}}_{\mathrm{E}} / \dot{\mathrm{V}}_{\mathrm{CO}_{2}}$ slope in a large cohort of children with CHD and to compare the results to ageand gender-matched healthy controls. We also intended to identify, in this specific population, the clinical and CPET variables associated with the $\dot{\mathrm{V}} / \dot{\mathrm{V}}_{\mathrm{CO}_{2}}$ slope.

\section{METHODS}

Study design. This cross-sectional study was carried out between November 2010 and September 2015 in two tertiary care pediatric and congenital cardiology reference centers (Centre 1: M3C Regional Paediatric and Congenital Cardiology Centre, Montpellier University Hospital, France; Centre 2: Paediatric Cardiology and Rehabilitation Centre, Institut-Saint-Pierre, Palavas-Les-Flots, France).

Patient population. All children aged 5 to $18 \mathrm{yr}$ old undergoing CPET in one of the two centers were assessed for inclusion, and eligible children were recruited after a regular pediatric cardiology outpatient visit. Two groups were identified as follows: children with CHD and control children.

In the CHD group, the anatomic and clinical classification of congenital heart diseases (ACC-CHD) was used to define the type of malformation (17). Patients with CHD were categorized into three severity classes, on the 32nd Bethesda classification, i.e., mild, moderate, and severe heart defects (36). The control group consisted of children referred for a non-severe functional symptom linked to exercise (murmur, palpitation, or dyspnea) or for a medical sports certificate. These children were classified in the control group only after a completely normal checkup, including physical examination, electrocardiogram, echocardiography, and spirometry. Children with any chronic disease, medical condition (cardiac, neurologic, respiratory, muscular, or renal), or medical treatment and those requiring any further specialized medical consultation were not eligible.

CPET procedures. CPET procedures in both the centers were harmonized before the study started. Both CPET laboratories used the same technical devices: pediatric face masks (Hans Rudolph, Shawnee, KS), a calibrated gas analyzer (Oxycon Pro, Jaeger, Erich Jaeger, Hoechberg, Germany), breath-to-breath measurement software (Windows V.98, Jaeger), 12-lead ECG equipment (CardioSoft, GE Healthcare, Little Chalfont, UK), a pulse oximeter (Nellcor, Medtronic, Fridley, MN), and a manual sphygmomanometer with adapted pediatric cuffs. Spirometry using a common gas device (Oxycon Pro, Jaeger, Erich Jaeger) was systematically performed before the exercise test with a flow volume curve and measurement of forced expiratory volume in $1 \mathrm{~s}$ (FEV1), forced vital capacity (FVC), and the FEV1/FVC ratio (FEV1\%); results were expressed as $Z$ scores from the spirometry reference equations (30).

Both centers used the same CPET pediatric cycle ergometer protocol adapted for children with CHD to obtain a homogeneous incremental overall duration between 8 and 12 min: a 1-min rest; a 3-min warm-up $(10-20 \mathrm{~W})$ in increments of 10,15 , or $20 \mathrm{~W}$ each minute; a pedaling rate of 60-80 revolutions per minute; a 3-min active recovery $(20 \mathrm{~W})$; and a 2 -min rest (33).

When the $\dot{\mathrm{V}}_{2 \max }$ did not reach a plateau, the peak $\dot{\mathrm{V}}_{2}$ was informed, as usual in pediatrics (5). $\dot{\mathrm{V}}_{2 \max }$ values were normalized in a percentage of the predicted $\dot{\mathrm{V}}_{2 \max }$ using normal values from study by Cooper et al. (11).

The first ventilatory anerobic threshold (VAT), e.g., the point at which minute ventilation increases disproportionally relative to $\mathrm{VO}_{2}$, was calculated using the V-slope method (6). When possible, we also identified the second ventilatory anaerobic threshold, also named respiratory compensation point ( $\mathrm{RCP})$, corresponding to the point of abrupt minute ventilation increase related to blood lactate accumulation (12). The RCP is rarely obtained in pediatric CPET, however, when identified, the section between RCP and $\dot{\mathrm{V}}_{\mathrm{O}_{2} \max }$ was not included in the $\dot{\mathrm{V}} \mathrm{E} / \dot{\mathrm{V}}_{\mathrm{CO}_{2}}$ slope calculation.

The $\dot{\mathrm{V}}_{\mathrm{E}} / \dot{\mathrm{V}}_{\mathrm{CO}_{2}}$ slope was calculated from breath-by-breath data and determined using linear regression of minute ventilation $\left(\dot{\mathrm{V}}_{\mathrm{E}}\right)$ and $\mathrm{CO}_{2}$ production $\left(\dot{\mathrm{V}}_{\mathrm{CO}}\right)$ obtained during incremental exercise $(27)$. As previously reported, two $\dot{\mathrm{V}}_{\mathrm{E}} / \dot{\mathrm{V}}_{\mathrm{CO}_{2}}$ slope values were measured for each subject (18). The overall $\dot{\mathrm{V}} \mathrm{E} / \dot{\mathrm{V}}_{\mathrm{CO}_{2}}$ slope value was measured from the beginning of incremental exercise (after the warm-up period) to maximum exercise (or RCP when present), and named " $\dot{\mathrm{V}} / \dot{\mathrm{V}}_{\mathrm{CO}_{2}}$ slope;" and the second value was measured from the beginning of incremental exercise to the first ventilatory anaerobic threshold (VAT), and named "نं $/ \dot{\mathrm{V}}_{\mathrm{CO}_{2} \text { [VAT] }}$ slope."

A single investigator manually calculated $\dot{\mathrm{V}}_{2 \max }, \mathrm{VAT}, \mathrm{RCP}$, and $\dot{\mathrm{V}} \mathrm{E} / \dot{\mathrm{V}}_{\mathrm{CO}}$ slope.

Physiological status in the CHD group. All the children underwent transthoracic echocardiography before CPET. According to hemodynamic findings and significant lesions shown by echocardiography, the main CHD physiological statuses were identified as follows:

- Left ventricle outflow tract (LVOT) obstacle was defined as aortic $\mathrm{V}_{\max }>2 \mathrm{~m} / \mathrm{s}$ and included subaortic, valvular aortic, and supravalvular aortic stenoses (26). Both values of mean and maximal gradients were measured.

- Significant aortic regurgitation (AR) and mitral regurgitation (MR) included moderate and severe regurgitations (26).

- Systemic ventricular dysfunction was defined by left ventricle systolic ejection fraction (LVEF) $<55 \%$ in left and single ventricles, or fractional area of change (FAC) $<33 \%$ in systemic right ventricles (19).

- Significant pulmonary regurgitation (PR) and tricuspid regurgitation (TR) included moderate and severe regurgitations (26).

- Right ventricle systolic pressure (RVSP) > $35 \mathrm{mmHg}$ defined increased RV pressure and was calculated using continuous-wave Doppler on tricuspid regurgitation and right atrium pressure assessment (14).

- Right ventricle outflow tract (RVOT) obstacle was defined as pulmonary $\mathrm{V}_{\max }>2 \mathrm{~m} / \mathrm{s}$ and involved infundibulum, pulmonary valve, pulmonary arterial trunk, and/or pulmonary arterial branches (26). Both values of mean and maximal RVOT gradients were measured.

Formal aspects. The study was conducted in compliance with the Good Clinical Practices and Declaration of Helsinki principles. The French Southern Mediterranean IV Ethics Committee (2009-A0042354) gave its approval. The study was registered on ClinicalTrials.gov (NCT01202916). Informed consent was obtained from all parents or legal guardians.

Statistics. The study population was described with means and standard deviations (SD) for quantitative variables and with frequencies for qualitative variables. Functional tests results (except for $Z$ scores) were described with means adjusted on gender and age and standard deviation. The continuous variables distributions were tested using the Shapiro-Wilk test. Quantitative variables were compared using the Student's $t$ test when the distribution was Gaussian and with the MannWhitney test, otherwise. For qualitative variables, groups were compared using the $\chi^{2}$ test or Fisher's exact test.

To compare all the CHD cases and controls, adjusted comparisons on gender and age were used (the number of controls was not sufficient for matching). For each type of CHD, age and gender-matched control comparisons were performed. For a given CHD case, all the controls with the same gender and age (exact year of age) were matched. The case with his (or her)-matched controls was considered as a cluster. Therefore, mixed models were performed in which the clusters were introduced as a random effect.

Correlations between $\dot{\mathrm{V}} \mathrm{E} / \dot{\mathrm{V}}_{\mathrm{CO}}$ s slope and other CPET parameters were assessed using Pearson's or Spearman's coefficients, depending on the distribution of variables. 
Table 1. Main demographic and CPET data: comparison between the CHD group and healthy subjects

\begin{tabular}{|c|c|c|c|}
\hline & CHD $(n=399)$ & Controls $(n=301)$ & $P$ Value \\
\hline Age, yr & $12.2 \pm 3.4$ & $11.1 \pm 2.6$ & $<0.01$ \\
\hline Height, cm & $150.8 \pm 17.6$ & $150.0 \pm 15.9$ & 0.48 \\
\hline Weight, $\mathrm{kg}$ & $44.2 \pm 15.8$ & $42.3 \pm 13.3$ & 0.23 \\
\hline Sex ratio (male/female) & 1.3 & 1.2 & 0.71 \\
\hline$\dot{\mathrm{V}} \mathrm{O}_{2 \max }$ predicts, $\%$ & $93.7 \pm 17.6$ & $106.0 \pm 17.6$ & $<0.001$ \\
\hline Percentage of predicted peak heart rate, $\%$ & $84.2 \pm 7.6$ & $90.1 \pm 7.6$ & $<0.001$ \\
\hline RER & $1.13 \pm 0.10$ & $1.13 \pm 0.10$ & 0.55 \\
\hline Maximum load, Watt & $90.0 \pm 44.2$ & $121.8 \pm 44.2$ & $<0.001$ \\
\hline FEV1 (Z-score) & $-0.46 \pm 1.29$ & $0.40 \pm 1.09$ & $<0.01$ \\
\hline FVC (Z-score) & $-0.44 \pm 1.42$ & $0.41 \pm 1.26$ & $<0.01$ \\
\hline FEV1/FVC (Z-score) & $0.06 \pm 1.34$ & $0.04 \pm 1.18$ & 0.63 \\
\hline Maximum tidal volume, $\mathrm{mL} / \mathrm{kg}$ & $28.10 \pm 5.54$ & $30.43 \pm 5.55$ & $<0.01$ \\
\hline Maximum respiratory frequency, $1 / \mathrm{min}$ & $52.48 \pm 9.96$ & $51.23 \pm 9.98$ & 0.11 \\
\hline $\mathrm{PET}_{\mathrm{CO}_{2}}$ at maximum exercise, $\mathrm{mmHg}$ & $31.93 \pm 4.54$ & $33.74 \pm 4.55$ & $<0.01$ \\
\hline
\end{tabular}

Values are means $\pm \mathrm{SD} ; n$, number of subjects. BMI, body mass index; CHD, congenital heart disease; CPET, cardiopulmonary exercise test; FEV1, forced expiratory volume in $1 \mathrm{~s}$; FEV1/FVC, Tiffeneau index; FVC, forced vital capacity; $\mathrm{PET}_{\mathrm{CO}_{2}}$, end-tidal $\mathrm{CO}_{2}$ pressure; RER, respiratory exchange ratio, $\dot{\mathrm{V}}_{2}$ max, maximal oxygen uptake.

To assess, globally and in each CHD group, the variation of $\dot{V}_{E} /$ $\dot{\mathrm{V}} \mathrm{CO}_{2}$ slope per year, a linear model adjusted on gender was used. The interaction age and case-control group being significant, the $\dot{\mathrm{V}} \mathrm{E} / \dot{\mathrm{V}}_{\mathrm{CO}}$ slope variation was estimated separately in the CHD and control groups. These results were illustrated with box plots according to age.

A multiple linear regression was used to identify the explanatory factors for $\dot{\mathrm{V}}_{\mathrm{E}} / \dot{\mathrm{V}}_{\mathrm{CO}}$ slope among children with $\mathrm{CHD}$ (all types of $\mathrm{CHD}$ combined). The clinically relevant variables with a $P$ value of $\leq 0.2$ in the univariate analysis were included in the model. The final model was determined using a backward selection with a removal level of 0.05 . Collinearity between factors was tested with variance inflation factors. The normality of residues in the final model was tested using the Shapiro-Wilk test.

The statistical significance was set at 0.05 , and analyses were performed using Statistical Analysis Systems Enterprise Guide version 4.3 (SAS Institute, Cary, NC).

\section{RESULTS}

Main population and CPET characteristics. During the 5-yr study period, 700 children were included in the study, i.e., 399 children with CHD and 301 healthy controls (Table 1). No families refused to participate. The center 1 and 2 included 225 and 475 children, respectively. Both groups were similar in terms of demographic data, except for age as children with CHD were slightly older than healthy controls $(12.2 \pm 3.4$ vs. $11.1 \pm 2.6 \mathrm{yr}$; $P<0.01$, respectively).

In the CHD group, the $\dot{\mathrm{V}}_{\mathrm{O}_{2 \max }}$, the percentage of predicted peak heart rate, the maximum load, FEV1, and FVC were significantly lower than in the control group. The respiratory exchange ratio and FEV1/FVC were similar in both groups.

Detailed echocardiographic findings for each CHD subgroup were reported in Table 2.

Table 2. Echocardiographic data in CHD subgroups

\begin{tabular}{|c|c|c|c|c|c|c|c|c|c|c|}
\hline & ACC-CHD Group & $n$ & $\begin{array}{l}\text { SVR } \\
(n, \%)\end{array}$ & $\begin{array}{c}\operatorname{RVSP}>35 \mathrm{mmHg} \\
(n, \%)\end{array}$ & $\begin{array}{l}\mathrm{TR} \\
(n, \%)\end{array}$ & $\begin{array}{l}\mathrm{PR} \\
(n, \%)\end{array}$ & $\begin{array}{l}\text { RVOT Obstacle } \\
\qquad(n, \%)\end{array}$ & $\begin{array}{l}\text { MR } \\
(n, \%)\end{array}$ & $\begin{array}{l}\mathrm{AR} \\
(n, \%)\end{array}$ & $\begin{array}{l}\text { LVOT Obstacle } \\
\qquad(n, \%)\end{array}$ \\
\hline 1 & Heterotaxy & 3 & $1(33)$ & $0(0)$ & $1(33)$ & $1(33)$ & $0(0)$ & $0(0)$ & $0(0)$ & $0(0)$ \\
\hline 2 & Anomalies of the venous return & 12 & $2(17)$ & $1(8)$ & $0(0)$ & $1(8)$ & $0(0)$ & $0(0)$ & $0(0)$ & $0(0)$ \\
\hline 3 & $\begin{array}{l}\text { Anomalies of the atria and interatrial } \\
\text { communications }\end{array}$ & 23 & $0(0)$ & $2(9)$ & $1(4)$ & $0(0)$ & $0(0)$ & $1(4)$ & $0(0)$ & $0(0)$ \\
\hline 4 & $\begin{array}{l}\text { Anomalies of the atrioventricular junctions } \\
\text { and valves }\end{array}$ & 24 & $0(0)$ & $3(13)$ & $9(38)$ & $0(0)$ & $0(0)$ & $6(25)$ & $1(4)$ & $3(12)$ \\
\hline 5 & $\begin{array}{l}\text { Complex anomalies of atrioventricular } \\
\text { connections }\end{array}$ & 4 & $1(25)$ & $1(25)$ & $0(0)$ & $0(0)$ & $1(25)$ & $0(0)$ & $0(0)$ & $0(0)$ \\
\hline 6 & Single ventricle & 22 & $4(21)$ & - & $4(18)$ & $0(0)$ & - & $2(9)$ & $2(9)$ & $0(0)$ \\
\hline 7 & Ventricular septal defects & 41 & $0(0)$ & $4(10)$ & $1(2)$ & $3(7)$ & $2(5)$ & $1(2)$ & $1(2)$ & $1(2)$ \\
\hline 8.1 & Transposition of the great arteries & 54 & $1(2)$ & $9(17)$ & $0(0)$ & $3(6)$ & $11(20)$ & $0(0)$ & $5(9)$ & $1(2)$ \\
\hline 8.2 & $\begin{array}{l}\text { Tetralogy of Fallot; truncus arteriosus; } \\
\text { pulmonary atresia; double outlet right } \\
\text { ventricle }\end{array}$ & 70 & $3(4)$ & $30(43)$ & $1(1)$ & $52(75)$ & $13(19)$ & $1(1)$ & $9(13)$ & $0(0)$ \\
\hline 8.5 & Aortic valve stenosis; Shone syndrome & 40 & $0(0)$ & $1(2)$ & $0(0)$ & $0(0)$ & $0(0)$ & $1(2)$ & $20(50)$ & $19(48)$ \\
\hline 8.6 & Pulmonary valve stenosis & 44 & $0(0)$ & $9(20)$ & $1(2)$ & $18(42)$ & $20(45)$ & $0(0)$ & $0(0)$ & $0(0)$ \\
\hline 9 & $\begin{array}{l}\text { Anomalies of the extrapericardial arterial } \\
\text { trunks }\end{array}$ & 59 & $0(0)$ & $1(2)$ & $0(0)$ & $0(0)$ & $0(0)$ & $0(0)$ & $3(5)$ & $7(12)$ \\
\hline 10 & $\begin{array}{l}\text { Congenital anomalies of the coronary } \\
\text { arteries }\end{array}$ & 3 & $0(0)$ & $0(0)$ & $0(0)$ & $1(33)$ & $0(0)$ & $0(0)$ & $0(0)$ & $0(0)$ \\
\hline
\end{tabular}

Results are expressed in numbers and percentage $(n, \%)$ for each CHD subgroup. AR, aortic regurgitation; CHD, congenital heart disease; LVOT, left ventricular outflow tract; MR, mitral regurgitation; PR, pulmonary regurgitation; RVOT, right ventricular outflow tract; RVSP, right ventricle systolic pressure; TR, tricuspid regurgitation; SVR, systemic ventricular dysfunction. 
$\dot{V}_{E} / \dot{V}_{\mathrm{CO}_{2}}$ slope results. In the control group, the mean $\dot{\mathrm{V}}_{\mathrm{E} /}$ $\dot{\mathrm{V}}_{\mathrm{CO}_{2}}$ slope was $29.6 \pm 4.3$. After gender and age were adjusted, the mean $\dot{\mathrm{V}} \mathrm{E} / \dot{\mathrm{V}}_{\mathrm{CO}_{2}}$ slope was significantly higher in the CHD group than in healthy subjects $(31.6 \pm 4.8$ vs. $29.3 \pm 4.8 ; P<$ 0.001 , respectively). In both the groups, the $\dot{\mathrm{V}} \mathrm{E} / \dot{\mathrm{V}}_{\mathrm{CO}}$ slope had a normal distribution and was not affected by gender.

When considering the CHD subgroups, the $\dot{\mathrm{V}}_{\mathrm{E}} / \dot{\mathrm{V}}_{\mathrm{CO}_{2}}$ slope was significantly higher (e.g., more impaired) in single ventricle (group 6), complex anomalies of ventriculoarterial connections (group 8.2), anomalies of the atrioventricular junctions and valves (group 4), transposition of the great arteries (group 8.1), and pulmonary valve stenosis (group 8.6) (Table 3, Fig. 1).

The $\dot{\mathrm{V}} \mathrm{E} / \dot{\mathrm{V}}_{\mathrm{CO}_{2}}$ slope according to the CHD physiological status was illustrated in Fig. 2. In the CHD population, the $\dot{V}_{\mathrm{E}} /$ $\dot{\mathrm{V}} \mathrm{CO}_{2}$ slope was higher in children with right heart anomalies, such as significant pulmonary regurgitation $(32.4 \pm 5.2$ vs. $31.0 \pm 5.8 ; P<0.01)$, tricuspid regurgitation (33.6 \pm 5.1 vs. $31.1 \pm 5.7 ; \mathrm{P} 0.04)$, right ventricular hypertension, and RVOT obstacle. Each 1-mmHg increase in the maximal gradient between the right ventricle and the pulmonary artery was associated with a $\dot{\mathrm{V}} \mathrm{E} / \dot{\mathrm{V}}_{\mathrm{CO}_{2}}$ slope increase of 0.08 points $(P<0.01)$. The $\dot{\mathrm{V}} / \dot{\mathrm{V}}_{\mathrm{CO}_{2}}$ slope was moderately lower in the presence of a LVOT obstacle. No statistical difference in terms of $\dot{\mathrm{V}} \mathrm{E} / \dot{\mathrm{V}}_{\mathrm{CO}_{2}}$ slope was found between the patients with CHD with and without systemic ventricular dysfunction, aortic regurgitation, or mitral regurgitation (Table 4).
The $\dot{\mathrm{V}} \mathrm{E} / \dot{\mathrm{V}}_{\mathrm{CO}}$ slope decrease with increased age was similar in the CHD and controls groups $(-0.63 \pm 0.08$ points/yr and $-0.68 \pm 0.09$ points/yr; $P$ 0.73, respectively) (Table 3 and Fig. 3).

The mean $\dot{\mathrm{V}}_{\mathrm{E}} / \dot{\mathrm{V}}_{\mathrm{CO}_{2}}$ [VAT] slope was significantly higher in the CHD group than in healthy subjects $(29.6 \pm 4.3$ vs. $27.4 \pm 3.9$; $P<0.01$, respectively) and similar between male and female subjects (Table 3). The $\dot{\mathrm{V}} \mathrm{E} / \dot{\mathrm{V}}_{\mathrm{CO}} \mathrm{C}_{2 \mathrm{VAT}]}$ slope differences observed between the CHD subgroups and controls were similar to those observed using the overall $\dot{\mathrm{V}} / \dot{\mathrm{V}}_{\mathrm{CO}_{2}}$ slope.

Factors associated with the $\dot{V} E / \dot{V} \mathrm{CO}_{2}$ slope. Overall, the $\dot{\mathrm{V}} \mathrm{E} /$ $\dot{\mathrm{V}}_{\mathrm{CO}_{2}}$ slope did not correlate with $\dot{\mathrm{V}}_{2}$ max predicts, for both the healthy controls $(\mathrm{r}=0.03, P=0.55)$ and children with $\mathrm{CHD}$ $(r=0.05, P=0.32)$. As expected, we found a positive correlation, in the CHD and controls groups, respectively, between $\dot{\mathrm{V}}_{\mathrm{E}} /$ $\dot{\mathrm{V}} \mathrm{CO}_{2}$ slope and respiratory frequency $(r=0.57, P<0.001$ and $r=0.56, P<0.001)$, and a negative correlation between $\dot{\mathrm{V}}_{\mathrm{E}} /$ $\dot{\mathrm{V}} \mathrm{CO}_{2}$ slope and $\mathrm{PET}_{\mathrm{CO}_{2}}(r=-0.64, P<0.001$ and $r=-0.79$, $P<0.001)$. However, in both the groups, we found a negative correlation between $\dot{\mathrm{V}}_{\mathrm{E}} / \dot{\mathrm{V}}_{\mathrm{CO}_{2}}$ slope and tidal volume $(r=-0.50$, $P<0.001$ and $r=-0.46, P<0.001)$.

In the CHD group, variables associated with a $\dot{V}_{\mathrm{E}} / \dot{\mathrm{V}}_{\mathrm{CO}_{2}}$ slope increase in both univariate and multivariate analyses were the body mass index (BMI), the presence of a RVOT obstacle, the number of cardiac catheter procedures, as well as low age, FVC, tidal volume, and $\mathrm{PET}_{\mathrm{CO}_{2}}$. The systemic ventricular dysfunction and the presence of genetic anomalies were not associated with any significant increase in $\dot{\mathrm{V}}_{\mathrm{E}} / \dot{\mathrm{V}}_{\mathrm{CO}_{2}}$ slope. In the CHD group,

Table 3. $\dot{V} E / \dot{V}_{C O}$ slope in the $C H D$ and control groups

\begin{tabular}{|c|c|c|c|c|c|c|c|c|c|c|c|c|c|}
\hline & & \multirow[b]{2}{*}{$N_{\mathrm{CHD}} / N_{\text {controls }}$} & \multicolumn{3}{|c|}{$\dot{\mathrm{V}}_{\mathrm{E}} / \dot{\mathrm{V}}_{\mathrm{CO}_{2}}$ Slope Means $\pm \mathrm{SD}$} & \multicolumn{4}{|c|}{$\dot{\mathrm{V}}_{\mathrm{E}} / \dot{\mathrm{V}}_{\mathrm{CO}}[\mathrm{VAT}]$ Slope Means $\pm \mathrm{SD}$} & \multicolumn{4}{|c|}{$\dot{\mathrm{V}}_{\mathrm{E}} / \dot{\mathrm{V}}_{\mathrm{CO}} 2$ Slope Variation Per Year* $\beta_{\text {coeff }} \pm \mathrm{SD}_{\beta}$} \\
\hline & & & $\mathrm{CHD}$ & Controls & $P \dagger$ & $\mathrm{CHD}$ & Cor & trols & $P \dagger$ & CHD & & Controls & $P$ \\
\hline \multirow{2}{*}{\multicolumn{2}{|c|}{$\begin{array}{l}\text { Total } \\
\text { Gender }\end{array}$}} & $399 / 301$ & $31.6 \pm 4.8$ & $29.3 \pm 4.8$ & $<0.01 *$ & $29.4 \pm 4.3$ & \multirow{2}{*}{\multicolumn{2}{|c|}{$27.0 \pm 4.3$}} & $<0.01 *$ & \multirow{2}{*}{\multicolumn{2}{|c|}{$-0.63 \pm 0.08 \S$}} & \multirow[t]{2}{*}{$-0.68 \pm 0.09 \S$} & 0.73 \\
\hline & & & & & & & & & & & & & \\
\hline \multicolumn{2}{|c|}{ Male } & $221 / 171$ & $31.1 \pm 6.0$ & $29.2 \pm 4.0$ & $<0.01$ & $28.7 \pm 5.4$ & \multicolumn{2}{|c|}{$27.2 \pm 3.8$} & 0.01 & \multicolumn{2}{|c|}{$-0.72 \pm 0.11 \S$} & $-0.90 \pm 0.10 \S$ & 0.30 \\
\hline \multicolumn{2}{|c|}{ Female } & $178 / 130$ & $31.5 \pm 5.4$ & $30.1 \pm 4.5$ & 0.01 & $29.6 \pm 5.2$ & & \pm 4.1 & $<0.01$ & $-0.51 \pm 0$ & $.12 \S$ & $43 \pm 0.15 \S$ & 0.67 \\
\hline \multicolumn{4}{|c|}{ ACC-CHD Group } & $\begin{array}{l}N_{\text {CHD }} / \\
N_{\text {controls }}\end{array}$ & CHD & Controls & $P$ व & CHD & Controls & $P q$ & CHD & Controls & $P \ddagger$ \\
\hline 1 & \multicolumn{3}{|c|}{ Heterotaxy } & $3 / 36$ & $31.5 \pm 3.9$ & $29.9 \pm 8.2$ & 0.45 & $30.1 \pm 3.4$ & $4 \quad 27.5 \pm 7.4$ & 0.16 & & & \\
\hline 2 & \multirow{2}{*}{\multicolumn{3}{|c|}{$\begin{array}{l}\text { Anomalies of the venous return } \\
\text { Anomalies of the atria and interatrial } \\
\text { communications }\end{array}$}} & $12 / 130$ & $30.0 \pm 5.0$ & $30.5 \pm 12.3$ & 0.66 & $27.3 \pm 4.8$ & $27.8 \pm 12.3$ & 0.62 & $-0.23 \pm 0.22$ & $-1.12 \pm 0.14 \S$ & $<0.01$ \\
\hline 3 & & & & $23 / 157$ & $29.7 \pm 4.1$ & $29.6 \pm 5.6$ & 0.91 & $27.4 \pm 4.1$ & $27.2 \pm 6.1$ & 0.75 & $-0.32 \pm 0.25$ & $-0.40 \pm 0.12 \S$ & 0.77 \\
\hline 4 & \multicolumn{3}{|c|}{$\begin{array}{l}\text { Anomalies of the atrioventricular } \\
\text { junctions and valves }\end{array}$} & $24 / 154$ & $31.9 \pm 4.7$ & $29.7 \pm 7.1$ & 0.02 & $29.5 \pm 4.0$ & $27.1 \pm 6.6$ & $<0.01$ & $0.45 \pm 0.37$ & $-0.83 \pm 0.12 \S$ & $<0.01$ \\
\hline 5 & \multicolumn{3}{|c|}{$\begin{array}{l}\text { Complex anomalies of atrioventricular } \\
\text { connections }\end{array}$} & $4 / 43$ & $31.1 \pm 3.5$ & $28.9 \pm 6.8$ & 0.19 & $28.1 \pm 3.4$ & $4 \quad 25.8 \pm 6.5$ & 0.16 & & & \\
\hline 6 & \multicolumn{3}{|c|}{ Single ventricle } & $22 / 191$ & $35.5 \pm 4.6$ & $29.6 \pm 8.4$ & $<0.01$ & $33.0 \pm 4.4$ & $4 \quad 27.2 \pm 7.7$ & $<0.01$ & $-0.29 \pm 0.29$ & $-0.79 \pm 0.11 \S$ & 0.08 \\
\hline 7 & \multicolumn{3}{|c|}{ Ventricular septal defects } & $41 / 269$ & $29.4 \pm 4.0$ & $29.1 \pm 5.5$ & 0.57 & $28.0 \pm 4.0$ & $26.8 \pm 5.5$ & 0.07 & $-0.44 \pm 0.24$ & $-0.51 \pm 0.10 \S$ & 0.73 \\
\hline 8.1 & \multicolumn{3}{|c|}{ Transposition of the great arteries } & $54 / 259$ & $31.5 \pm 5.1$ & $29.6 \pm 8.1$ & $<0.01$ & $29.4 \pm 4.6$ & $6 \quad 27.1 \pm 7.4$ & $<0.01$ & \multirow{2}{*}{$\begin{array}{l}-1.11 \pm 0.28 \S \\
-0.87 \pm 0.18 \S\end{array}$} & $-0.71 \pm 0.10 \S$ & 0.13 \\
\hline 8.2 & \multicolumn{3}{|c|}{$\begin{array}{l}\text { Tetralogy of Fallot; truncus arteriosus; } \\
\text { pulmonary atresia; double outlet } \\
\text { right ventricle }\end{array}$} & $70 / 288$ & $33.7 \pm 4.8$ & $29.8 \pm 7.3$ & $<0.01$ & $31.3 \pm 4.6$ & $627.4 \pm 7.1$ & $<0.01$ & & $-0.72 \pm 0.09 \S$ & 0.40 \\
\hline 8.5 & \multicolumn{3}{|c|}{ Aortic valve stenosis; Shone syndrome } & $40 / 258$ & $29.2 \pm 4.4$ & $29.2 \pm 7.2$ & 0.95 & $26.8 \pm 4.2$ & $26.8 \pm 7.2$ & 0.91 & $-0.59 \pm 0.20 \S$ & $-0.69 \pm 0.10 \S$ & 0.64 \\
\hline 8.6 & \multicolumn{3}{|c|}{ Pulmonary valve stenosis } & $44 / 280$ & $31.4 \pm 4.4$ & $29.3 \pm 6.9$ & $<0.01$ & $29.6 \pm 4.2$ & $27.1 \pm 6.4$ & $<0.01$ & \multirow{2}{*}{$\begin{array}{l}-1.03 \pm 0.28 \S \\
-0.64 \pm 0.15 \S\end{array}$} & $-0.65 \pm 0.09 \S$ & 0.09 \\
\hline 9 & $\begin{array}{r}\text { Anor } \\
\text { tru }\end{array}$ & ies of the extrape & icardial arterial & $59 / 289$ & $29.5 \pm 4.5$ & $29.3 \pm 7.0$ & 0.67 & $27.4 \pm 4.2$ & $26.9 \pm 6.3$ & 0.40 & & $-0.69 \pm 0.09 \S$ & 0.76 \\
\hline 10 & $\begin{array}{r}\text { Cong } \\
\text { art }\end{array}$ & $\begin{array}{l}\text { tal anomalies of } \\
\text { es }\end{array}$ & he coronary & $3 / 29$ & $34.4 \pm 4.7$ & $29.4 \pm 10.3$ & 0.03 & $30.6 \pm 3.9$ & $27.4 \pm 9.4$ & 0.06 & & & \\
\hline
\end{tabular}

ACC-CHD, anatomical and clinical classification of congenital heart diseases; CHD, congenital heart disease; $\dot{V}_{\mathrm{E}} / \dot{\mathrm{V}}_{\mathrm{CO}}[\mathrm{VAT}]$ slope, measured from the first level of exercise (after the warm-up period) to the first ventilatory anaerobic threshold (VAT). *Gender-adjusted regression coefficient for a variation of 1 yr of age $(\mathrm{mL} / \mathrm{kg} / \mathrm{min} /$ year $)$; $†$ Comparisons of $\dot{\mathrm{VE}} / \dot{\mathrm{V}}_{\mathrm{CO}_{2}}$ slope between all CHD and the controls after adjustment for age and gender; $\$$ Age $\times$ group interaction test;

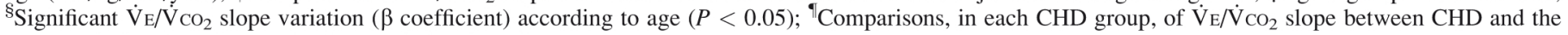
age-matched and gender-matched controls (random cluster). 
Fig. 1. $\dot{\mathrm{V}} / \dot{\mathrm{V}}_{\mathrm{CO}_{2}}$ slope according to the anatomical and clinical CHD classification. Box plots of the $\dot{\mathrm{V}} \mathrm{E} / \dot{\mathrm{V}}_{\mathrm{CO}_{2}}$ slope in the CHD subgroups (as defined in Table 2) and in the healthy subjects. Bottom and top of the box represent the first and third quartiles. Inside the box, the band represents the second quartile (median), and the circle represents the mean. Whiskers represent the minimum and maximum values. ACC-CHD, anatomical and clinical classification of congenital heart diseases; CHD, congenital heart disease.

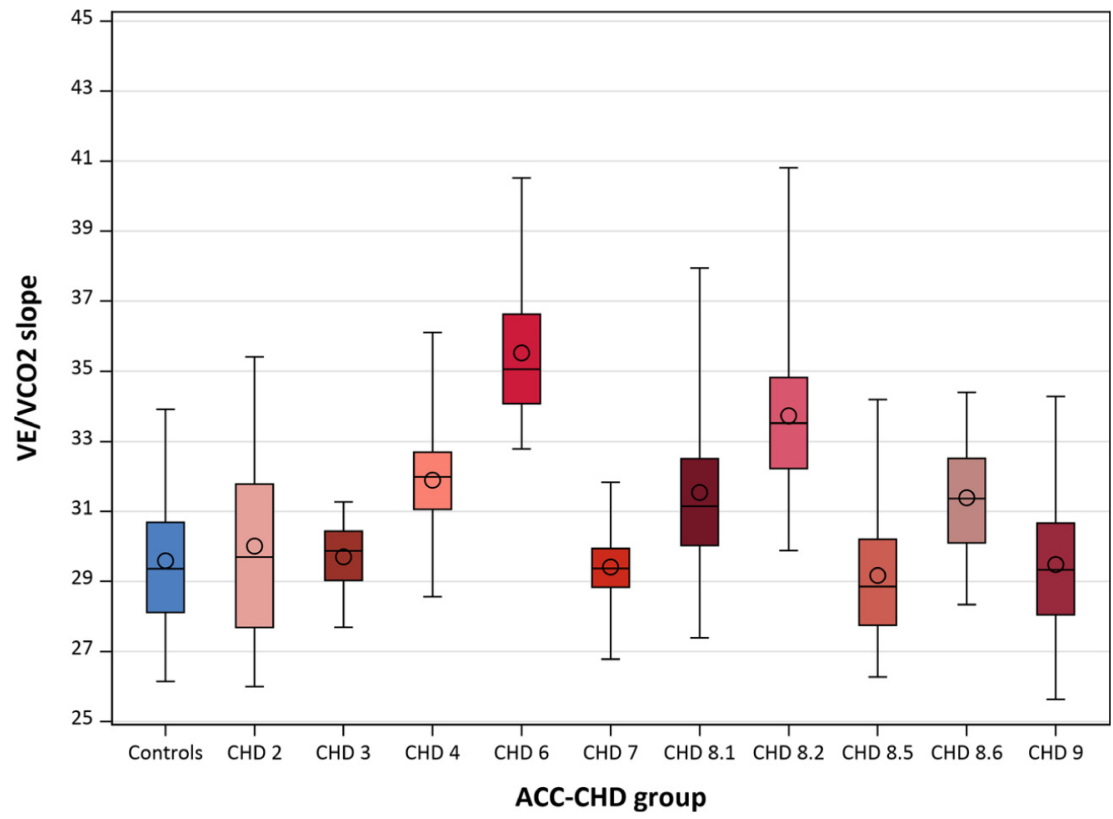

the final multivariate model (including age, BMI, the presence of a RVOT obstacle, the number of cardiac catheter procedures, FVC, tidal volume, and $\mathrm{PET}_{\mathrm{CO}_{2}}$ ) explained $70 \%$ of the variance in the $\dot{\mathrm{V}} \mathrm{E} / \dot{\mathrm{V}}_{\mathrm{CO}}$ slope (Table 4).

\section{DISCUSSION}

This multicenter controlled study of a large cohort of 700 children presented the $\dot{\mathrm{V}}_{\mathrm{E}} / \dot{\mathrm{V}}_{\mathrm{CO}_{2}}$ slope values of 399 children with CHD compared with 301 healthy controls and analyzed, for the first time in this population, the clinical determinants of the $\dot{\mathrm{V}} \mathrm{E} / \dot{\mathrm{V}}_{\mathrm{CO}_{2}}$ slope.

Overall, the $\dot{\mathrm{V}} \mathrm{E} / \dot{\mathrm{V}}_{\mathrm{CO}}$ slope was significantly higher in children with CHD than in healthy subjects, although their aerobic fitness was excellent, with a mean $\dot{\mathrm{V}}_{2 \max }$ of nearly $94 \%$ of the predicted values. In the adult population, the $\dot{V}_{\mathrm{E}} /$ $\dot{\mathrm{V}} \mathrm{CO}_{2}$ slope has emerged as a useful prognostic maker for heart failure, especially in patients with submaximal CPET for which maximal effort is not reached and $\dot{\mathrm{V}}_{\mathrm{O}_{2 \max }}$ is interpretable $(24,27)$. In the pediatric population, the $\dot{\mathrm{V}}_{\mathrm{E}} / \dot{\mathrm{V}}_{\mathrm{CO}_{2}}$ slope is less widely used. Yet, we previously showed that the $\dot{\mathrm{V}} \mathrm{E} / \dot{\mathrm{V}}_{\mathrm{CO}_{2}}$ slope was associated with the quality of life of children with CHD (4), and could be used as a surrogate outcome in CHD drug trials (1). In this study, we showed that the two methods to calculate the $\dot{\mathrm{V}}_{\mathrm{E}} / \dot{\mathrm{V}}_{\mathrm{CO}_{2}}$ slope, e.g., to VAT or to maximum exercise, brought similar results, which confirms that $\dot{\mathrm{V}} \mathrm{E} / \dot{\mathrm{V}}_{\mathrm{CO}}$ slope might also be of interest in submaximal CPET in children (31).
Fig. 2. $\dot{\mathrm{V}}_{\mathrm{E}} / \dot{\mathrm{V}}_{\mathrm{CO}_{2}}$ slope according to the $\mathrm{CHD}$ physiological status. Box plots of the $\dot{\mathrm{V}}_{\mathrm{E}} / \dot{\mathrm{V}}_{\mathrm{CO}_{2}}$ slope in the CHD physiological groups and in the healthy subjects. Bottom and top of the box represent the first and third quartiles. Inside the box, the band represents the second quartile (median), and the circle represents the mean. Whiskers represent the minimum and maximum values. AR/MR, moderate or severe aortic regurgitation and/or moderate or severe mitral regurgitation; CHD, congenital heart disease; LVOT, left ventricular outflow tract; PR/TR, moderate or severe pulmonary regurgitation and/or moderate or severe tricuspid regurgitation; RVOT, right ventricular outflow tract; RVSP, right ventricle systolic pressure; SV, single ventricle; SVR systemic ventricular dysfunction.

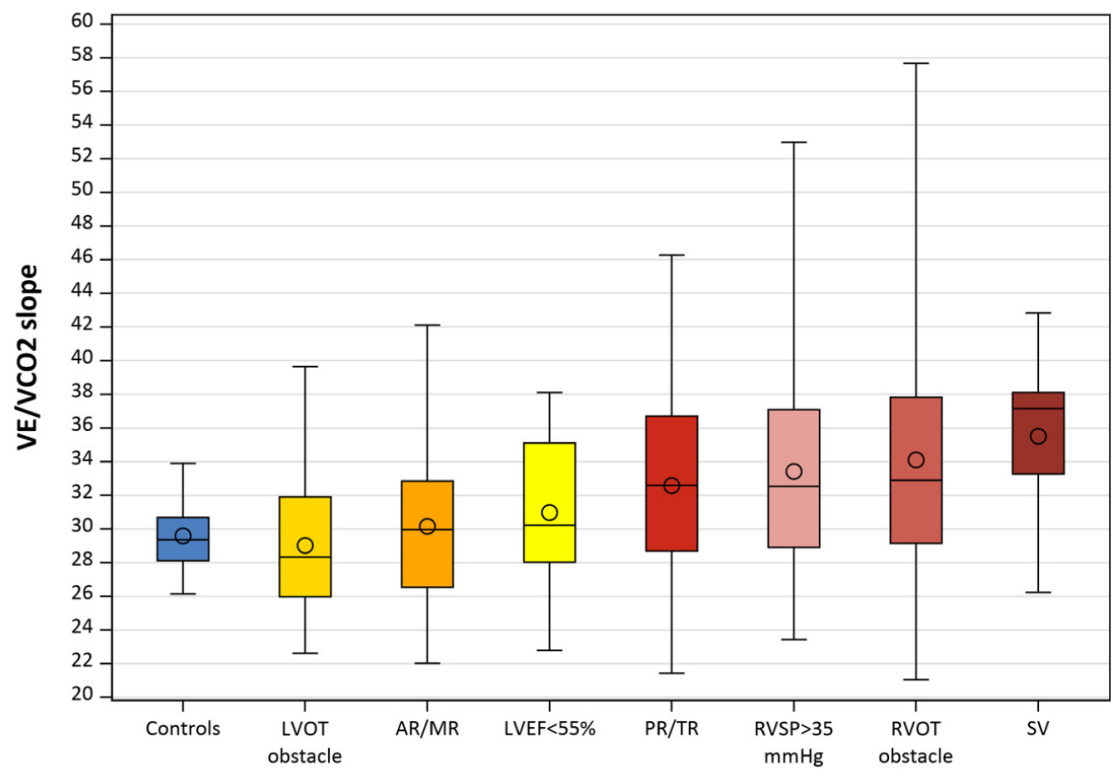

Physiological CHD status 
Table 4. $\dot{V} E / \dot{V} \mathrm{CO}_{2}$ slope explanatory variables in the $\mathrm{CHD}$ group

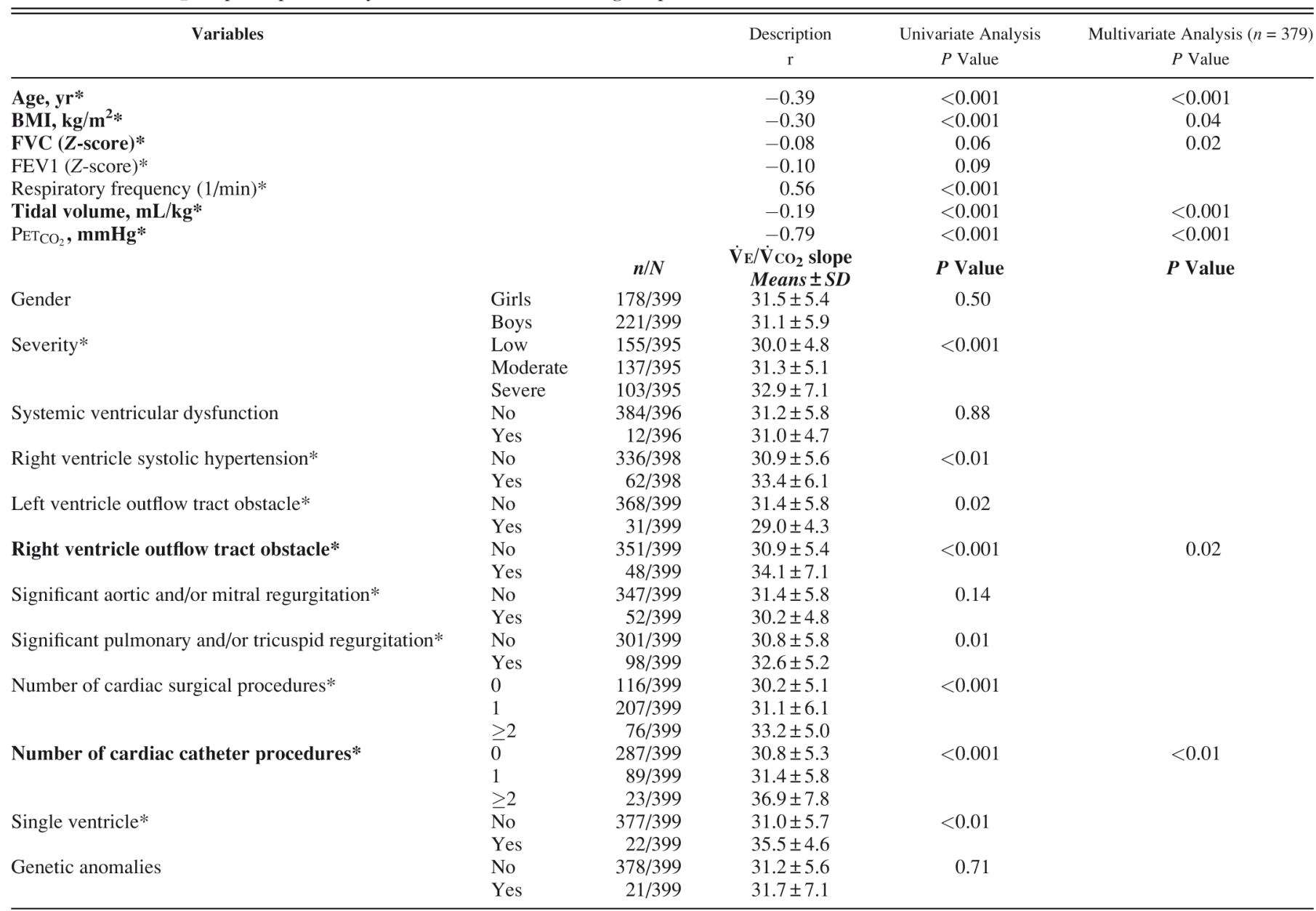

Variables associated with the $\dot{\mathrm{V}}_{\mathrm{E}} / \dot{\mathrm{V}}_{\mathrm{CO}_{2}}$ slope in both univariable and multivariable analyses are marked in bold. BMI, body mass index; CHD, congenital heart disease; FEV1, forced expiratory volume in $1 \mathrm{~s} ; \mathrm{FVC}$, forced vital capacity; SD, standard deviation. *Candidate variables for multivariate analysis.

As opposed to $\dot{\mathrm{V}}_{\mathrm{O}_{2 \max }}$, the $\dot{\mathrm{V}} \mathrm{E} / \dot{\mathrm{V}}_{\mathrm{CO}_{2}}$ slope is not influenced by gender (20), as observed in our pediatric cohort. However, we found higher $\dot{\mathrm{V}} \mathrm{E} / \dot{\mathrm{V}} \mathrm{CO}_{2}$ slope values in younger children, as their breath rate during exercise to eliminate $\mathrm{CO}_{2}$ is higher and their $\mathrm{PaCO}_{2}$ set point lower than older children (25). Nevertheless, standard values of $\dot{\mathrm{V}} \mathrm{E} / \dot{\mathrm{V}}_{\mathrm{CO}_{2}}$ slope have not been fully established. Interestingly, we found a mean $\dot{\mathrm{V}}_{\mathrm{E}} / \dot{\mathrm{V}}_{\mathrm{CO}_{2}}$ value of 29 in the control group, which is in line with Rhodes et al. (32), who reported normal values $<28$. From a cohort of 228 children aged 12-17, Blanchard et al. (8) recently proposed reference values for $\dot{\mathrm{V}}_{\mathrm{E}} / \dot{\mathrm{V}}_{\mathrm{CO}}$ slope, using adjustment for gender, height, and weight, but as opposed to our study, not for age. Moreover, our results are consistent with the study from Giardini et al. (16), describing the existence of a physiological decrease of ventilatory response to exercise in the second decade of life in healthy children, as well as with the study from Ten Harkel et al. (34), reporting the linear equation of $\dot{\mathrm{V}} \mathrm{E} / \dot{\mathrm{V}}_{\mathrm{CO}_{2}}$ slope in healthy girls and boys $(-0.64 \times$ age +38$)$.

As might have been anticipated, the $\dot{\mathrm{V}}_{\mathrm{E}} / \dot{\mathrm{V}}_{\mathrm{CO}_{2}}$ slope was predominantly affected in CHD with impaired pulmonary perfusion, such as single ventricle $\left(\dot{\mathrm{V}} \mathrm{E} / \mathrm{V}_{\mathrm{CO}_{2}}\right.$ slope $\left.\approx 36\right)$ and complex right heart $\mathrm{CHDs}\left(\dot{\mathrm{V}}_{\mathrm{E}} / \dot{\mathrm{V}}_{\mathrm{CO}_{2}}\right.$ slope $\left.\approx 34\right)$. Moreover, multivariate analysis found that the $\dot{\mathrm{V}} \mathrm{E} / \dot{\mathrm{V}}_{\mathrm{CO}}$ slope was associated with the presence of a RVOT obstacle or the number of cardiac catheter procedures, which reflect the complex nature of such CHDs (2). We may hypothesize that the impairment of ventilatory efficiency in those patients involve ventilation-perfusion mismatch $(22,32)$. This mismatch from inadequate pulmonary perfusion of normally ventilated alveoli associated with $\dot{\mathrm{V}} \mathrm{E} / \dot{\mathrm{V}}_{\mathrm{CO}_{2}}$ slope increase has been previously described in pulmonary arterial hypertension (31) and adult heart failure (35). Our study brings some additional support to this ventilation-perfusion mismatch theory, as $\dot{\mathrm{V}} \mathrm{E} / \dot{\mathrm{V}}_{\mathrm{CO}}$ slope was increased in single ventricle and right heart significant anomalies (RVOT obstruction, pulmonary and tricuspid regurgitations, and right ventricle hypertension), e.g., in patients most concerned with pulmonary blood flow maldistribution during exercise. Other mechanisms behind $\dot{\mathrm{V}}_{\mathrm{E}} / \dot{\mathrm{V}}_{\mathrm{CO}_{2}}$ slope increase by ventilation-perfusion mismatch involve an inadequate ventilation (37), as in obstructive lung diseases like cystic fibrosis (13), or an altered $\mathrm{PaCO}_{2}$ set point and increased chemosensitivity, as in many cardiopulmonary diseases. However, those mechanisms should probably not be applied to our pediatric population, for which no significant obstructive lung disease was observed and no severe impairment in aerobic fitness, and no severe heart failure could suggest the existence of an altered $\mathrm{PaCO}_{2}$ set point (2).

The $\dot{\mathrm{V}} / \dot{\mathrm{V}}_{\mathrm{CO}_{2}}$ slope was not significantly impaired in simple repaired shunts, such as atrial septal defects and ventricular 
Fig. 3. $\dot{V}_{\mathrm{E}} / \dot{\mathrm{V}}_{\mathrm{CO}}$ slope variation with age in the children with $\mathrm{CHD}$ and healthy children. Box plots of $\dot{\mathrm{V}} \mathrm{E} / \dot{\mathrm{V}}_{\mathrm{CO}_{2}}$ slope as a function of age (yr). Bottom and top of the box represent the first and third quartiles. Inside the box, the band represents the second quartile (median), and the circle represents the mean. Whiskers represent the minimum and maximum values. Linear curves represent the mean $\mathrm{VE} / \mathrm{VCO}_{2}$ slope variation with age.

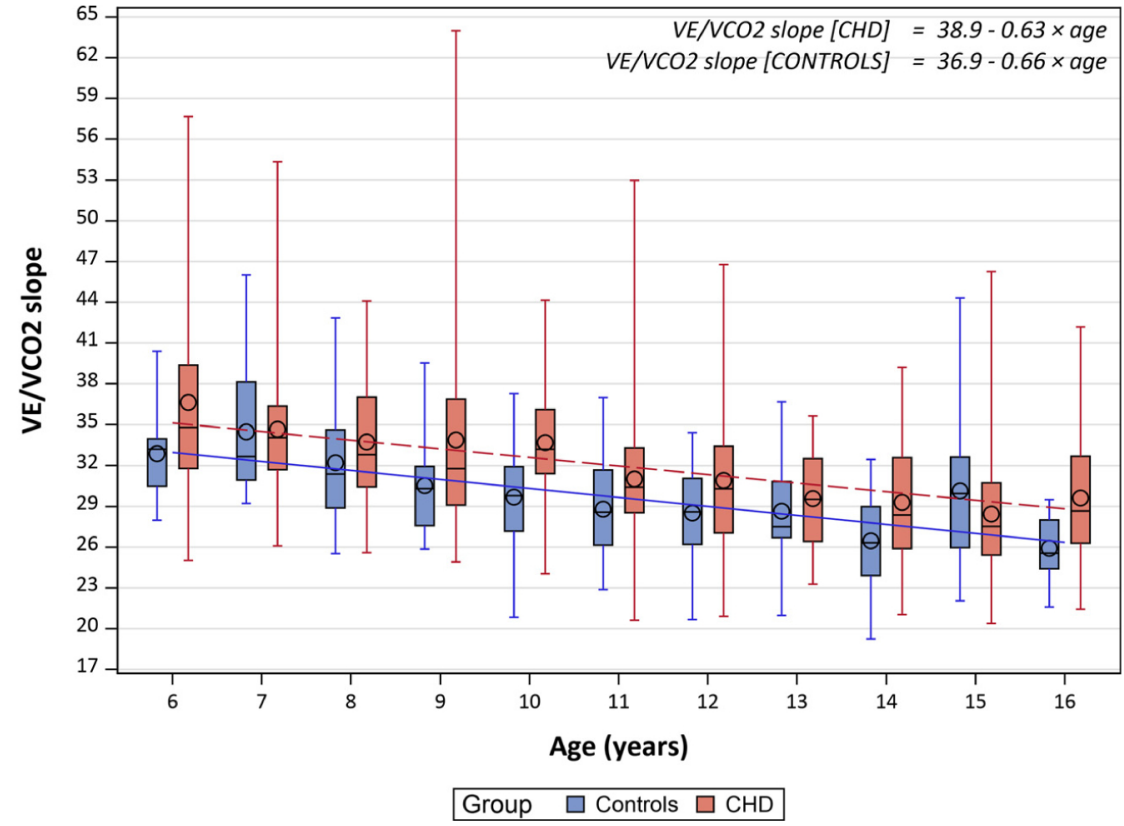

septal defects, which represent the leading cause of CHDs. Similarly, the $\dot{\mathrm{V}}_{\mathrm{E}} / \dot{\mathrm{V}}_{\mathrm{CO}}$ slope in children with left heart diseases was not impaired. Indeed, in most left heart CHDs and simple repaired shunts, the early surgical repair with usually the least sequelae avoids any situation of heart failure and results in a normal aerobic fitness (2). Consequently, $\mathrm{PaCO}_{2}$ set point and chemosensitivity are not altered, and the $\dot{\mathrm{V}} / \mathrm{V}_{\mathrm{CO}_{2}}$ slope remains stable.

Interestingly, this study identified some potentially modifiable variables associated with an impaired $\dot{\mathrm{V}} / \mathrm{V}_{\mathrm{CO}_{2}}$ slope, such as low values of BMI, FVC, tidal volume, and $\mathrm{PET}_{\mathrm{CO}_{2}}$. Indeed, the most complex CHDs are associated with malnutrition and restrictive lung disease related to sarcopenia, which result in muscular deconditioning. Therefore, such children may benefit from cardiac rehabilitation programs, using active nutritional management, respiratory muscle strength physiotherapy, and conventional aerobic training (3).

Study limitation. This study was performed in tertiary care centers and may not represent CHD in the general population. Despite a large cohort of nearly 400 children with CHD, the absence of relationship between cardiac status and $\dot{\mathrm{V}}_{\mathrm{E}} / \dot{\mathrm{V}}_{\mathrm{CO}_{2}}$ slope in some small subgroups may be based on the lack of statistical power, such as in 12 patients with systemic ventricular dysfunction.

The control group was recruited at the hospital and may not be considered as healthy as if they were recruited from the general population. We thus called them the control children.

The cross-sectional design of the study provided no data on the evolution of the $\dot{\mathrm{V}} \mathrm{E} / \dot{\mathrm{V}}_{\mathrm{CO}_{2}}$ slope per subject over time. Indeed, further cohort studies will need to determine the prognostic value of $\dot{\mathrm{V}} / \dot{\mathrm{V}}_{\mathrm{CO}_{2}}$ slope in pediatric cardiology.

Conclusion. The mean $\dot{\mathrm{V}} / \mathrm{V}_{\mathrm{CO}_{2}}$ slope was significantly higher in children with CHD than in healthy matched subjects. The $\dot{\mathrm{V}}_{\mathrm{E}} / \dot{\mathrm{V}}_{\mathrm{CO}_{2}}$ slope is sensible to mismatch from inadequate pulmonary perfusion of normally ventilated alveoli and seems to be an independent and complementary variable of $\dot{V}_{\mathrm{O}_{2 \max }}$ in children with CHD. This mismatch appeared to be predominant in single ventricles and right heart residual lesions, suggesting pulmonary blood flow maldistribution during exercise in such physiological situations. Therefore, $\dot{\mathrm{V}}_{\mathrm{E}} / \dot{\mathrm{V}}_{\mathrm{CO}}$ slope may be a useful tool, complementary to $\dot{\mathrm{V}}_{2 \text { max }}$, in the follow-up of children with single ventricle or right heart CHDs.

Further cohort studies will need to determine the prognostic value of $\dot{\mathrm{V}} \mathrm{E} / \dot{\mathrm{V}}_{\mathrm{CO}_{2}}$ slope in pediatric cardiology and to determine standard values in this population.

\section{ACKNOWLEDGMENTS}

Clinical trial registration is located at ClinicalTrials.gov NCT01202916 (post-results).

\section{GRANTS}

This study was funded by Montpellier University Hospital Clinical Research Program (PHRC 8422).

\section{DISCLOSURES}

No conflicts of interest, financial or otherwise, are declared by the authors.

\section{AUTHOR CONTRIBUTIONS}

A.G., S.M. and P.A. conceived and designed research; A.G., H.H. and M.P. analyzed data; A.G. and P.A. interpreted results of experiments; H.H. prepared figures; A.G., M.P., S.M. and P.A. drafted manuscript; A.G., S.G., S.M. and P.A. edited and revised manuscript; A.G., H.H., M.P., S.G., S.M. and P.A. approved final version of manuscript.

\section{REFERENCES}

1. Amedro P, Gavotto A, Abassi H, Picot M-C, Matecki S, MalekzadehMilani S, Levy M, Ladouceur M, Ovaert C, Aldebert P, Thambo J-B, Fraisse A, Humbert M, Cohen S, Baruteau A-E, Karsenty C, Bonnet D, Hascoet S; SV-INHIBITION study investigators. Efficacy of phosphodiesterase type 5 inhibitors in univentricular congenital heart disease: the SVINHIBITION study design. ESC Heart Fail 7: 747-756, 2020. doi:10.1002/ ehf 2.12630 .

2. Amedro P, Gavotto A, Guillaumont S, Bertet H, Vincenti M, De La Villeon G, Bredy C, Acar P, Ovaert C, Picot M-C, Matecki S. 
Cardiopulmonary fitness in children with congenital heart diseases versus healthy children. Heart 104: 1026-1036, 2018. doi:10.1136/heartjnl-2017312339.

3. Amedro P, Gavotto A, Legendre A, Lavastre K, Bredy C, De La Villeon G, Matecki S, Vandenberghe D, Ladeveze M, Bajolle F, Bosser G, Bouvaist H, Brosset P, Cohen L, Cohen S, Corone S, Dauphin C, Dulac Y, Hascoet S, Iriart X, Ladouceur M, Mace L, Neagu O-A, Ovaert C, Picot M-C, Poirette L, Sidney F, Soullier C, Thambo J-B, Combes N, Bonnet D, Guillaumont S. Impact of a centre and home-based cardiac rehabilitation program on the quality of life of teenagers and young adults with congenital heart disease: The QUALI-REHAB study rationale, design and methods. Int $J$ Cardiol 283: 112-118, 2019. doi:10.1016/j.ijcard. 2018.12.050.

4. Amedro P, Picot MC, Moniotte S, Dorka R, Bertet H, Guillaumont S, Barrea C, Vincenti M, De La Villeon G, Bredy C, Soulatges C, Voisin M, Matecki S, Auquier P. Correlation between cardio-pulmonary exercise test variables and health-related quality of life among children with congenital heart diseases. Int J Cardiol 203: 1052-1060, 2016. doi:10.1016/j. ijcard.2015.11.028

5. Barker AR, Williams CA, Jones AM, Armstrong N. Establishing maximal oxygen uptake in young people during a ramp cycle test to exhaustion. Br J Sports Med 45: 498-503, 2011. doi:10.1136/bjsm.2009.063180.

6. Beaver WL, Wasserman K, Whipp BJ. A new method for detecting anaerobic threshold by gas exchange. J Appl Physiol (1985) 60: 2020-2027, 1986. doi:10.1152/jappl.1986.60.6.2020.

7. Blais S, Berbari J, Counil F-P, Dallaire F. A systematic review of reference values in pediatric cardiopulmonary exercise testing. Pediatr Cardiol 36: 1553-1564, 2015. doi:10.1007/s00246-015-1205-6.

8. Blanchard J, Blais S, Chetaille P, Bisson M, Counil FP, Huard-Girard T, Berbari J, Boulay P, Dallaire F. New reference values for cardiopulmonary exercise testing in children. Med Sci Sports Exerc 50: 1125-1133, 2018. doi:10.1249/MSS.0000000000001559.

9. Cicoira M, Zanolla L, Franceschini L, Rossi A, Golia G, Zamboni M, Tosoni P, Zardini P. Skeletal muscle mass independently predicts peak oxygen consumption and ventilatory response during exercise in noncachectic patients with chronic heart failure. J Am Coll Cardiol 37: 2080-2085, 2001. doi:10.1016/S0735-1097(01)01306-7.

10. Cooper DM, Kaplan MR, Baumgarten L, Weiler-Ravell D, Whipp BJ, Wasserman K. Coupling of ventilation and $\mathrm{CO}_{2}$ production during exercise in children. Pediatr Res 21: 568-572, 1987. doi:10.1203/00006450198706000-00012.

11. Cooper DM, Weiler-Ravell D, Whipp BJ, Wasserman K. Aerobic parameters of exercise as a function of body size during growth in children. $J$ Appl Physiol 56: 628-634, 1984. doi:10.1152/jappl.1984.56.3.628.

12. Davis JA, Whipp BJ, Wasserman K. The relation of ventilation to metabolic rate during moderate exercise in man. Eur J Appl Physiol Occup Physiol 44: 97-108, 1980. doi:10.1007/BF00421087.

13. Di Paolo M, Teopompi E, Savi D, Crisafulli E, Longo C, Tzani P, Longo F, Ielpo A, Pisi G, Cimino G, Simmonds NJ, Neder JA, Chetta A, Palange P. Reduced exercise ventilatory efficiency in adults with cystic fibrosis and normal to moderately impaired lung function. $J$ Appl Physiol (1985) 127: 501-512, 2019. doi:10.1152/japplphysiol.00030.2019.

14. Galiè N, Humbert M, Vachiery J-L, Gibbs S, Lang I, Torbicki A, Simonneau G, Peacock A, Vonk Noordegraaf A, Beghetti M, Ghofrani A, Gomez Sanchez MA, Hansmann G, Klepetko W, Lancellotti P, Matucci M, McDonagh T, Pierard LA, Trindade PT, Zompatori M, Hoeper M; ESC Scientific Document Group. 2015 ESC/ERS Guidelines for the Diagnosis and Treatment of Pulmonary Hypertension: The Joint Task Force for the Diagnosis and Treatment of Pulmonary Hypertension of the European Society of Cardiology (ESC) and the European Respiratory Society (ERS): endorsed by: Association for European Paediatric and Congenital Cardiology (AEPC), International Society for Heart and Lung Transplantation (ISHLT). Eur Heart $J$ 37: 67-119, 2016. doi:10.1093/ eurheartj/ehv317.

15. Gavotto A, Vandenberghe D, Abassi H, Bertet H, Macioce V, Picot MC, Guillaumont S, Matecki S, Amedro P. Oxygen uptake efficiency slope in children with congenital heart disease versus healthy children. Arch Cardiovasc Dis 12, Suppl: 153, 2020. doi:10.1016/j.acvdsp.2019.09.307.

16. Giardini A, Odendaal D, Khambadkone S, Derrick G. Physiologic decrease of ventilatory response to exercise in the second decade of life in healthy children. Am Heart $J$ 161: 1214-1219, 2011. doi:10.1016/j.ahj. 2011.03.008.

17. Houyel L, Khoshnood B, Anderson RH, Lelong N, Thieulin A-C, Goffinet F, Bonnet D; EPICARD Study group. Population-based evaluation of a suggested anatomic and clinical classification of congenital heart defects based on the International Paediatric and Congenital Cardiac Code. Orphanet J Rare Dis 6: 64, 2011. doi:10.1186/1750-1172-6-64.

18. Ingle L, Goode K, Carroll S, Sloan R, Boyes C, Cleland JGF, Clark AL. Prognostic value of the $V_{E} / V_{\mathrm{CO} 2}$ slope calculated from different time intervals in patients with suspected heart failure. Int J Cardiol 118: 350-355, 2007. doi:10.1016/j.ijcard.2006.07.105

19. Khattab K, Schmidheiny P, Wustmann K, Wahl A, Seiler C, Schwerzmann M. Echocardiogram versus cardiac magnetic resonance imaging for assessing systolic function of subaortic right ventricle in adults with complete transposition of great arteries and previous atrial switch operation. Am J Cardiol 111: 908-913, 2013. doi:10.1016/j.amjcard.2012. 11.044 .

20. Lee J-S, Jang S-I, Kim S-H, Lee S-Y, Baek J-S, Shim W-S. The results of cardiopulmonary exercise test in healthy Korean children and adolescents: single center study. Korean J Pediatr 56: 242-246, 2013. doi:10.3345/ kjp.2013.56.6.242.

21. Marcadet D-M, Pavy B, Bosser G, Claudot F, Corone S, Douard H, Iliou M-C, Vergès-Patois B, Amedro $P$, Le Tourneau T, Cueff C, Avedian T, Solal AC, Carré F. French Society of Cardiology Guidelines on Exercise Tests (part 2): indications for exercise tests in cardiac diseases. Arch Cardiovasc Dis 112: 56-66, 2019. doi:10.1016/j.acvd.2018.07.001.

22. Mezzani A, Giordano A, Moussa NB, Micheletti A, Negura D, Saracino A, Canal E, Giannuzzi P, Chessa M, Carminati M. Hemodynamic, not ventilatory, inefficiency is associated with high $\mathrm{VE} / \mathrm{VCO}_{2}$ slope in repaired, noncyanotic congenital heart disease. Int J Cardiol 191: 132-137, 2015. doi:10.1016/j.ijcard.2015.04.285.

23. Müller J, Böhm B, Semsch S, Oberhoffer R, Hess J, Hager A. Currently, children with congenital heart disease are not limited in their submaximal exercise performance. Eur J Cardiothorac Surg 43: 1096-1100, 2013. doi:10.1093/ejcts/ezs712.

24. Myers J, Arena R, Dewey F, Bensimhon D, Abella J, Hsu L, Chase P, Guazzi M, Peberdy MA. A cardiopulmonary exercise testing score for predicting outcomes in patients with heart failure. Am Heart J 156: 1177-1183, 2008. doi:10.1016/j.ahj.2008.07.010.

25. Nagano Y, Baba R, Kuraishi K, Yasuda T, Ikoma M, Nishibata K, Yokota M, Nagashima M. Ventilatory control during exercise in normal children. Pediatr Res 43: 704-707, 1998. doi:10.1203/00006450199805000-00021

26. Nishimura RA, Otto CM, Bonow RO, Carabello BA, Erwin JP III, Guyton RA, O'Gara PT, Ruiz CE, Skubas NJ, Sorajja P, Sundt TM III, Thomas JD, Anderson JL, Halperin JL, Albert NM, Bozkurt B, Brindis RG, Creager MA, Curtis LH, DeMets D, Guyton RA, Hochman JS, Kovacs RJ, Ohman EM, Pressler SJ, Sellke FW, Shen W-K, Stevenson WG, Yancy CW; American College of Cardiology; American College of Cardiology/American Heart Association; American Heart Association. 2014 AHA/ACC guideline for the management of patients with valvular heart disease: a report of the American College of Cardiology/American Heart Association Task Force on Practice Guidelines. J Thorac Cardiovasc Surg 148: e1-e132, 2014. doi:10.1016/j.jtcvs.2014.05.014.

27. Paolillo S, Veglia F, Salvioni E, Corrà U, Piepoli M, Lagioia R, Limongelli G, Sinagra G, Cattadori G, Scardovi AB, Metra M, Senni M, Bonomi A, Scrutinio D, Raimondo R, Emdin M, Magrì D, Parati G, Re F, Cicoira M, Minà C, Correale M, Frigerio M, Bussotti M, Battaia E, Guazzi M, Badagliacca R, Di Lenarda A, Maggioni A, Passino C, Sciomer S, Pacileo G, Mapelli M, Vignati C, Clemenza F, Binno S, Lombardi C, Filardi PP, Agostoni P; MECKI Score Research Group. Heart failure prognosis over time: how the prognostic role of oxygen consumption and ventilatory efficiency during exercise has changed in the last 20 years. Eur J Heart Fail 21: 208-217, 2019. doi:10.1002/ejhf.1364.

28. Parazzi PLF, Marson FAL, Ribeiro MAGO, Schivinski CIS, Ribeiro JD. Ventilatory efficiency in children and adolescents: a systematic review. Dis Markers 2015: 546891, 2015. doi:10.1155/2015/546891.

29. Ponikowski P, Chua TP, Anker SD, Francis DP, Doehner W, Banasiak W, Poole-Wilson PA, Piepoli MF, Coats AJS. Peripheral chemoreceptor hypersensitivity: an ominous sign in patients with chronic heart failure. Circulation 104: 544-549, 2001. doi:10.1161/hc3101.093699.

30. Quanjer PH, Stanojevic S, Cole TJ, Baur X, Hall GL, Culver BH, Enright PL, Hankinson JL, Ip MSM, Zheng J, Stocks J; ERS Global Lung Function Initiative. Multi-ethnic reference values for spirometry for the 3-95-yr age range: the global lung function 2012 equations. Eur Respir J 40: 1324-1343, 2012. doi:10.1183/09031936.00080312.

31. Rausch CM, Taylor AL, Ross H, Sillau S, Ivy DD. Ventilatory efficiency slope correlates with functional capacity, outcomes, and disease severity in 
pediatric patients with pulmonary hypertension. Int J Cardiol 169: 445-448, 2013. doi:10.1016/j.ijcard.2013.10.012.

32. Rhodes J, Ubeda Tikkanen A, Jenkins KJ. Exercise testing and training in children with congenital heart disease. Circulation 122: 1957-1967, 2010. doi:10.1161/CIRCULATIONAHA.110.958025.

33. Takken T, Blank AC, Hulzebos EH, van Brussel M, Groen WG, Helders PJ. Cardiopulmonary exercise testing in congenital heart disease: equipment and test protocols. Neth Heart J 17: 339-344, 2009. doi:10.1007/ BF03086280.

34. Ten Harkel AD, Takken T. Normal values for cardiopulmonary exercise testing in children. Eur J Cardiovasc Prev Rehabil 18: 676-677, 2011. doi:10.1177/1741826711410517.
35. Van Iterson EH, Johnson BD, Borlaug BA, Olson TP. Physiological dead space and arterial carbon dioxide contributions to exercise ventilatory inefficiency in patients with reduced or preserved ejection fraction heart failure. Eur J Heart Fail 19: 1675-1685, 2017. doi:10.1002/ejhf.913.

36. Warnes CA, Liberthson R, Danielson GK Jr, Dore A, Harris L, Hoffman JI, Somerville J, Williams RG, Webb GD. Task force 1: the changing profile of congenital heart disease in adult life. $J$ Am Coll Cardiol 37: 1170-1175, 2001. doi:10.1016/S0735-1097(01)01272-4.

37. Weatherald J, Sattler C, Garcia G, Laveneziana P. Ventilatory response to exercise in cardiopulmonary disease: the role of chemosensitivity and dead space. Eur Respir J 51: 1700860, 2018. doi:10.1183/13993003.008602017. 